\title{
trilhando um caminho de estudos sobre o rock no brasil
}

Tracing a path of rock studies in Brazil Sheyla Castro Diniz ${ }^{1}$

Resumo: Resenha do livro Nas trilhas do rock: experimentalismo e mercado musical (2018), organizado por Rainer Gonçalves Sousa.

Palavras-chave: estudos sobre o rock; indústria cultural; contracultura

Abstract: Review of the book Nas trilhas do rock: experimentalismo e mercado musical (2018), organized by Rainer Gonçalves Sousa.

Keywords: rock studies; cultural industry; counterculture

1 Doutora em Sociologia da Cultura pela Unicamp. Contato: sheyladiniz@yahoo.com.br. 
Bem-vinda desde o início do século XX no noticiário jornalístico, mas até não muito tempo vista por alguns como um assunto menor ou inferior no campo acadêmico brasileiro, hoje a música popular gravada já conta com um número significativo de pesquisas. Sua relevância concomitantemente cultural, histórica e sociológica tem orientado abordagens diversas na grande área das Humanidades, apontando para uma tendência interdisciplinar que aos poucos ganha quórum. Mas no país berço do samba, da Bossa Nova, da chamada MPB, do Tropicalismo e de outras incontáveis expressões de nossa música popular ${ }^{2}$, há ainda um déficit considerável para com manifestações musicais nascidas além Brasil. Uma dessas lacunas, se bem que contemplada por iniciativas anteriores, recebe agora mais uma incursão em Nas trilhas do rock: experimentalismo e mercado musical, coletânea lançada em 2018, pela editora Kelps, sob a organização de Rainer Gonçalves Souza³.

Resultante de uma miríade de trocas socioculturais no mundo anglo-saxão do pós-Segunda Guerra, o rock tem algumas de suas variadas facetas reveladas ao longo dos dez ensaios/capítulos que compõem o livro, cinco dedicados àquele produzido no eixo Inglaterra-Estados Unidos e os outros àquele que, num contexto de mundialização da cultura prenunciado desde o fim dos anos de 1960, foi levado a cabo por músicos brasileiros. Divididos, portanto, em Parte 1 ("Rock internacional") e Parte 2 ("Rock nacional"), os textos podem ser lidos aleatoriamente sem nenhum prejuízo. Obedecem, no entanto, a uma cronologia que favorece a compreensão dos diferentes meandros do rock no decorrer das décadas de 1960 a 1980, período em que alguns de seus ícones são evidenciados.

Não por acaso, o papel seminal do compositor de "Subterranean homesick blues" - só pari passu com o dos Beatles - é tema do texto de abertura: "O fantasma da eletricidade: Bob Dylan, o fim do rock and roll e o nascimento do rock moderno". Rodrigo Merheb demonstra como Dylan captou transformações de sua época e antecipou estilos, nadando quase sempre 2 O termo música popular - que alguns preferem chamar de música popular gravada ou música popular comercial - se sedimentou para discernir a música industrializada/de entretenimento, ou produzida e reproduzida nas malhas da indústria cultural, da música de concerto (ou erudita) e daquela tida como folclórica. Para uma discussão a respeito, ver: MIDDLETON, 1990.

3 Os ensaios reunidos no livro foram apresentados originalmente por seus autores no I Colóquio Nas trilhas do rock: experimentalismo e mercado musical, evento promovido no segundo semestre de 2016 pelo Grupo de Estudos Culturais (GECu) da UNESP (campus de Franca). O GECu é coordenado pelo professor José Adriano Fenerick e conta com historiadores, sociólogos, músicos e demais pesquisadores. 
contra a maré de certas convenções. "Fantasma da eletricidade" diz respeito ao episódio, assombroso aos olhos dos puristas - para ficar na metáfora -, em que Dylan, certo de que deveria seguir novos rumos, apresenta-se com guitarra elétrica no Festival de Newport (1965), chocando fãs que tinham na protest song, da qual ele fora ídolo ao lado de Joan Baez, um símbolo de oposição à Guerra do Vietnã e da luta pacifista pró-Direitos Civis nos Estados Unidos. De ritmo dançante e considerado por muitos como meramente comercial e até vulgar, o rock é redimensionado nas mãos do artista, que na geração beat também vai buscar o tom agora ácido e existencial de suas canções. Incorporando o que antes estava na literatura de gente como Ginsberg e Kerouac, Dylan, entretanto, segundo o autor, não embrenhou na psicodelia musical tal qual verificada em São Francisco, Los Angeles ou Londres. Apesar de todas as inovações, ele nunca teria abdicado por inteiro "da tradição musical [a canção nutrida no folk] que formou sua sensibilidade quando ainda era um adolescente no meio-oeste americano" (p. 38).

Personagem principal, Dylan e sua música às vezes se perdem, contudo, na tentativa de condensar outras tantas questões e acontecimentos ao mesmo tempo imbricados e paralelos. Frisa, por exemplo, o fato de o rock moderno carecer da miscigenação racial à qual o rock ' $n$ ' roll inicialmente se propunha em figuras do porte de um Chuck Berry. Visão hegemônica na literatura, ainda falta um trabalho brasileiro que a conteste, mesmo que parcialmente, ao focalizar exceções à regra como ninguém menos que Jimi Hendrix. De todo modo, retomando argumentos desenvolvidos no seu $O$ som da revolução (2012), Merheb, partindo de Dylan, tece um panorama resumido dos anos iniciais da contracultura, uma problemática que - como não poderia deixar de ser numa coletânea como esta - está presente em quase todos os ensaios ${ }^{4}$.

Preparado o terreno, José Adriano Fenerick trata, em seguida, de "Rock e vanguarda nos anos 6o: uma dialética possível". Mesmo não se atendo propriamente ao conceito, não unívoco, de vanguarda - algo feito em outros trabalhos (por ex. FENERICK, 2017) cuja referência comum é Andreas Huyssen (1986) -, o autor aponta que do mesmo chão político e social em que nasceu a contracultura, em suas múltiplas ramificações, despontou um cruzamento frutífero entre rock, produto da indústria cultural, e vanguarda,

4 Como apontou James Perone, a música - notadamente o rock - esteve envolvida em e por cada faceta do fenômeno contracultural, desempenhando papeis nas vidas de, provavelmente, todos os que o engrossaram (cf. PERONE, 2004: 7). 
atrelada paradoxalmente à arte autônoma modernista5. Para abordar a possível dialética, analisa e compara discos exemplares: Sgt. Pepper's Lonely Hearts Club Band (1967), dos Beatles, e We're only in it for the money (1968), de Frank Zappa and The Mothers of Invention.

Álbum conceitual e de estúdio, no qual a tecnologia empregada é instrumento, Sgt. Pepper's, desde a capa às canções variegadas, exprime a ideia, ou o conceito, de que é um show ao vivo da banda fictícia do "Sargento Pimenta". Colagens eletroacústicas, compassos e encadeamentos inusuais, silêncios à la John Cage e a participação anticonvencional de uma orquestra sinfônica, para não falar do flerte com a música indiana, traço típico do misticismo contracultural, são alguns dos aspectos que ambientam o show imaginário. Disco em que o experimentalismo e os procedimentos de vanguarda são a "norma", estranha, portanto, o acorde perfeito de Mi Maior que encerra a sua última faixa, "A day in the life". Para Fenerick, tal final é índice da adesão inconteste dos Beatles "à ideologia da não violência e da solução mediada dos conflitos" (p. 49). Restaria, porém, cotejar essa interpretação com o vozerio em looping e nonsense que realmente arremata Sgt. Pepper's. Aí talvez resida o ápice da sua longevidade ${ }^{6}$.

Se os Beatles, contudo, e apesar de todo o caos sonoro, sugeriam naquele acorde a opção pelo ideário pacifista que embalou o lado flower power da contracultura, esse não foi o leitmotiv de Frank Zappa e seu conjunto. Bebendo nas mesmas fontes vanguardistas da música aleatória e eletroacústica, mas com resultados distintos, We're only in it for the money é, ainda que não só, uma notável paródia de Sgt. Pepper's, o que 5 Conforme Peter Bürger (2008), cuja Teoria da Vanguarda trata das chamadas "vanguardas históricas" do século XX, a revolta da vanguarda nasce impreterivelmente do subsistema da arte autônoma modernista. Como crítica e autocrítica da "instituição-arte" na sociedade burguesa, sua meta é restituir à arte a "práxis vital", isto é, o elo entre "arte e vida" cindido pelo alto modernismo. Projeto só realizável, portanto, sob um estágio de acentuado desenvolvimento dos meios técnicos de produção, é justamente nessa tentativa de a vanguarda superar a dicotomia, almejando transformar não só a arte como a vida cotidiana, que Andreas Huyssen identifica o germe do que denominou de "dialética oculta entre vanguarda, tecnologia e cultura de massa" (cf. 1986; 1997).

6 A conclusão é de Lorenzo Mammi: "Finalmente, fragmentos indecifráveis de uma conversa encerram o disco. Como, nesse ponto, o sulco do vinil de Sgt. Pepper's não continua sua marcha em espiral em direção ao centro, mas se fecha em círculo, esse fragmento sem sentido continua ao infinito, até alguém levantar a agulha (nas edições recentes em CD é impossível manter essa particularidade, que foi substituída por uma banal dissolvência). Assim, tanto no registro das alturas, como no das durações, o disco literalmente não acaba. É ilimitado em tempo e em frequências" (MAMMI, 2004). 
se vê logo na capa e no título sarcástico. Em que pese sua persona freak, igualmente associada à contracultura, Zappa em nada se assemelhava ao neorromantismo predominante no movimento hippie e, em boa medida, encontrado no álbum do quarteto de Liverpool. Embora este também enfrentasse a condição reificada do músico na indústria cultural, aquele despia o rock de qualquer compromisso apaziguador, expondo-o como mercadoria não obstante o seu caráter não menos radical. Para Zappa, segundo Fenerick, não haveria síntese possível entre rock e vanguarda. Já a intensão dos Beatles em Sgt. Pepper's seria outra: elevar o rock à categoria de obra de arte modernista (p. 52-53).

O Sgt. Pepper's continua rendendo assunto em "She's leaving home: o processo de feminilização das canções dos Beatles, o movimento feminista e a contracultura". Fenômeno plural e heterodoxo, a contracultura não passou incólume pelos padrões sexistas de sua época, como argumenta Vanessa Pironato Milani. Se tais padrões se reproduziam, por exemplo, entre hippies, a despeito da liberação sexual/comportamental que lhes foi característica, é no rock, canal mediatizado por excelência da contracultura dos sixties, onde a autora os identifica: seja na constatação de que as bandas eram majoritariamente formadas por homens, na associação entre "som agressivo e masculinidade", nas letras expressamente machistas ou que, de modo sutil, subjugavam a mulher, ou em imagens corriqueiras em que guitarristas exibiam o instrumento como uma espécie de trunfo fálico. Em meio a tudo isso, porém, uma gradativa "feminilização do rock" adquire tônus com o avançar dos anos de 1960, graças, sobretudo, ao fortalecimento do movimento feminista (p. 55-69).

Para além da presença cada vez mais marcante de, sobretudo, cantoras no rock, essa feminilização diz respeito a uma mudança de perspectiva em relação à mulher (p. 58). É nesse sentido que Milani comenta algumas canções dos Beatles, dando destaque para "Run for your life", de Rubber soul (1965), e para a que intitula o seu ensaio. A primeira, bem ao gosto do rock ' $n$ ' roll teenager da fase inicial do conjunto, e, em sua avaliação, a mais explicitamente machista dessa safra, apresenta um eu-lírico masculino que se julga no direito de decidir sobre a vida da namorada, cogitando até matá-la caso ela desafiasse sua "mente ciumenta". "She's leaving home" é francamente distinta. Faixa de Sgt. Pepper's (1967), álbum que inaugura a guinada não só musical como visual do quarteto, a garota é agora protagonista. Tomada 
pela sensibilidade hippie e drop-out, ela já não se satisfaz com o bemestar proporcionado por sua família burguesa, optando fugir de casa para conquistar sua liberdade e autonomia (p. 72-74).

Apesar de deixar um pouco de lado o que a música poderia acrescentar às análises, já que se atém especialmente às letras, a autora toca num tema não raras vezes ignorado, contribuindo com quem pretende estudar o rock e/ou a contracultura sob o prisma feminino. No escopo do que aborda, não perde de vista a importância essencial de Yoko Ono na vida e na carreira pós-Beatles de John Lennon, Yoko que, do parceiro, nunca foi "apêndice", um dos motivos pelo qual enfrentou toda sorte de misoginia e xenofobia (p. 76). Ao leitor suscita o desejo de captar - e talvez aí esteja um esboço de pesquisa - qual teria sido a contrapartida do rock ao movimento feminista que lhe lapidou o olhar. Noutros termos, e para ficar só entre mulheres, em que medida Yoko, Janis Joplin, Nico, Grace Slick e tantas outras, de dentro mesmo da indústria cultural, foram diametralmente influentes na composição de lutas feministas da sociedade de seu tempo.

É comum o entendimento de que a contracultura, tal como se configurou nos Estados Unidos e na Inglaterra, não resistiu para muito além do ocaso dos anos de 1960. Quando não abafada pela repressão, imposta a variadas frentes, diluiu-se ou se degenerou sob a hegemonia do mercado capitalista. O rock, que no sistema capitalista sempre esteve consubstanciado, vai naturalmente se transformar junto a esse processo. Ricardo Arruda procura apreendê-lo em "Saltando para as montanhas sombrias: Led Zeppelin, Tolkien e contracultura (1966-74)", concentrando-se, para isso, em "Battle of evermore", faixa do quarto disco da famosa banda britânica conhecido pelo nome de Led Zeppelin IV (1971). Tributária nalguma medida do nascente rock progressivo, um dos inúmeros desdobramentos do rock na década de 1970, a música exalaria certa "atmosfera barroca" a envolver o jogo de contrastes da "batalha eterna", como diz o título, do bem contra o mal. Mal, todavia, realçado pela escolha das figuras que aparecem na letra, todas pinçadas da literatura fantástica de J. J. R. Tolkien (1892-1973), criador da célebre trilogia O senhor dos anéis (1954-55).

O enredo então fabuloso e um tanto bucólico, visível inclusive na imagem pastoril que ilustra a capa do disco, não mencionada - um velhote corcunda com um punhado de gravetos no dorso -, guardaria um passado idealizado que jamais voltará. Narrada, contudo, no presente, daí também seu caráter 
épico, a canção, segundo Arruda, consistiria numa alegoria para a recessão do welfare state na Inglaterra e para a citada decadência da contracultura, fosse aquela alinhada à Nova Esquerda, cujo potencial anticapitalista teria minguado com a ascensão dos "novos movimentos sociais" - o que é controverso -, fosse aquela ligada ao neorromantismo hippie, cada vez mais desfigurado pela moda e o consumo. Por mais que recorresse justamente ao universo místico e mitológico rente à experiência hippie, "Battle of evermore" não vislumbraria aí possibilidades de superação. Seu tom geral, conclui o autor, é de "resignação com tal melancolia" (p. 97).

Cabe atentar que não foi noutro senão num contexto de profunda crise, com o qual mais parecia se conformar que exatamente denunciar nessa canção específica, que o Led Zeppelin alcançou o posto de uma das bandas de maior notoriedade do pós-68. Seria o "mundo em distopia", repleto de lendas prémodernas e seres sobrenaturais, a fórmula do sucesso de parte do rock que desponta no período? Rainer Gonçalves Sousa responde parcialmente a essa questão em "What is this that stands before me?: Black Sabbath, contracultura e teratologia (1970-78)", ensaio que fecha a Parte 1 da coletânea.

Precursores do chamado heavy metal, os ingleses do Black Sabbath teriam rompido com toda e qualquer mensagem de esperança associada ao rock dos anos de 1960. Canções, visual e performances teratológicas nada tinham a ver com a ideia de "cultura solar" disseminada pelo Summer of Love californiano e outras tantas manifestações que ainda hoje alimentam os discursos predominantes sobre contracultura. É justo esse o problema que Sousa se propõe a enfrentar. Acionando estudiosos do fenômeno contracultural, defende que o Black Sabbath foi antes o resultado de uma confluência de fatores próprios à geração dos sixties do que a negação pura e simples de tudo aquilo do qual destoava (p. 129). Com arranjos soturnos e agressivos, letras falavam de sexo, drogas, ocultismo e até da Guerra do Vietnã, sob leituras, no entanto, impregnadas de hedonismo, loucura, ceticismo, desespero, destruição e terror. Mas se a contracultura se fez tanto de utopia quanto de distopia, conforme uma perita no assunto (cf. WHITELEY, 2012), teria sido através desta última que Ozzy Osbourne e parceiros não só expuseram como criticaram as contradições de seu momento histórico, explorando o "satanismo" como principal alegoria. Oriunda da cultura de massa, tal estética teria conferido ao conjunto uma imagem quase religiosa, 
sugestiva de um ethos anticristão e, portanto, anti-hegemônico (p. 123-4), aparente paradoxo sobre o qual nunca é demais reforçar que o diabo é pop.

Para além do que cada texto explora em particular, a originalidade dessa primeira parte do livro reside de antemão no fato de que traz à tona artistas cuja bibliografia está majoritariamente acessível em inglês. Num movimento inverso àquele dos brasilianistas, os autores engrossam um contingente ainda parco de pesquisadores no Brasil. Mostram que, mais que simplesmente um gênero musical, mais que a soma de atitudes e comportamentos da juventude de uma época, e mais que tão somente um segmento de mercado - para retomar as palavras de Márcia Tosta Dias na quarta-capa -, o rock, forma cultural 7 complexa, teve alcance e impacto mundial, o que, por si só, justifica tomá-lo como objeto de reflexão visando a um público brasileiro mais amplo.

Quando repercutiu aqui nos trópicos de meados da década de 1960, momento em que muitos o acusavam de ser a representação máxima do imperialismo cultural, o rock já estava prestes a contribuir com a dilatação da ideia até então preconcebida de MPB. Em "Tropicália, rock e experimentalismo", ensaio que dá início à Parte 2, Daniela Vieira dos Santos revisita o movimento que, ao mesmo tempo em que valorizou tradições musicais brasileiras, foi em grande medida responsável por tal dilatação. Em que isso pese, dentre os tropicalistas não haveria homogeneidade estética tampouco ideológica, premissa que a autora desenvolve a partir das canções "Eles" (LP Caetano Veloso, 1968) e "Dom Quixote" (LP Mutantes, 1969). A afronta de Caetano aos "engajados da música popular" derivava de um projeto político consciente, ao passo que Os Mutantes se pautaram muito mais no bom humor, no pastiche, no deboche descarado e no chamado desbunde como sinônimo de falta de comprometimento ${ }^{8}$. Ainda assim, ambos teriam declarado "luto aos diversificados projetos nacionais-populares que informaram a MPB dos anos 1960" (p. 147). Valeria considerar, porém, em até que ponto isso procederia

7 Sobre a noção de forma cultural, concebida sempre a partir das relações imbricadas entre processos socioculturais mais amplos e manifestações artísticas (suas linguagens, padrões, convenções e/ou estilos passíveis de reconhecimento), verWILLIAMS, 1992: 147-178; 2001: 58; 2016. 8 Empregado originalmente por militantes da luta armada para desqualificar companheiros desertores, o desbunde se tornou um dos diversos nomes dados à contracultura no Brasil. Apesar de designar ausência de compromisso político e ser uma gíria normalmente associada ao modelo de vida hippie, sua circulação entre o fim da década de 1960 e início da de 1970 assumiu configurações ambivalentes (cf. DINIZ, 2017). 
no caso dos Mutantes. Se só faz luto quem está na iminência de superar alguma perda, a banda, ao contrário do Caetano pré-tropicalista, jamais se nutriu do nacional-popular ${ }^{9}$, exceto para desdenhá-lo junto à perspectiva revolucionária que orientou boa parcela dos cancionistas do período.

No ensaio, cujas análises evidenciam os procedimentos experimentais que, distintos, estruturam as duas canções, ganha também algum destaque a discussão acerca do alegado caráter vanguardista do tropicalismo, do qual a autora discorda. Baseando-se no estudo de Peter Bürger (2008), entende que o conceito de vanguarda é incompatível com manifestações produzidas no bojo da indústria cultural. Reconhece, no entanto, que ao experimentalismo tropicalista não faltou recursos vanguardistas (p. 137) $)^{10}$.

Avançando para o princípio da década de 1970 - já findado o tropicalismo, mas cujo legado foi inconteste para uma parcela da produção musical que o sucedeu -, Cleber Sberni Junior nos convida a percorrer "O caminho das pedras: rock e MPB na revista Rolling Stone edição brasileira (1972)". Tendo à frente figuras como Ezequiel Neves, Ana Maria Bahiana e, como editor-chefe, Luiz Carlos Maciel, responsável por outras tantas iniciativas associadas à contracultura no Brasil - como, por exemplo, a famosa "Coluna Underground" (1969-71) no semanário O Pasquim -, a Rolling Stone dedicou-se especialmente à música, comportando-se, segundo o autor, como "vanguarda das novas tendências musicais que iam do rock ao pop e à MPB" (p. 158). Em sua breve existência de 37 edições, a revista traduziu e publicou matérias lançadas originalmente pela matriz norte-americana - à qual deveria pagar royalties -, além de, naturalmente, divulgar trabalhos de artistas brasileiros, fossem aqueles que, de algum modo, davam continuidade e/ou radicalizavam propostas tropicalistas, fossem bandas de rock stricto sensu (O Terço, Módulo 1000, A Bolha, para citar apenas três dentre inúmeras outras que despontaram no período). As análises nos

9 Sobre o ideário ou a cultura nacional-popular no pensamento de esquerda e nas artes dos anos de 1960, ver, por exemplo, CHAUÍ, 1982; CONTIER, 1998; RIDENTI, 2000; NAPOLITANO, 2001.

10 Sobre a Teoria da vanguarda de Peter Bürger, conferir nota n. 3. Particularmente, e dialogando aqui com o ensaio anterior de José Adriano Fenerick, vejo nas contribuições de Andreas Huyssen (1986; 1997) uma ferramenta mais apropriada para se pensar as possíveis relações entre música popular e vanguarda, noção cuja complexidade não é a mesma num país periférico como o Brasil. O que havia de moderno e de alta cultura no tropicalismo proveio em larga medida da pop art (incluindo o rock) e das chamadas vanguardas ou neovanguardas brasileiras do pós-Segunda Guerra (concretismo, neoconcretismo, Música Nova, Nova Objetividade, etc.), todas elas, em maior ou menor escala, não excluídas do mercado cultural em expansão. 
levam a concluir que, apesar desse empenho jornalístico naqueles "anos de chumbo" e, simultaneamente, de "milagre econômico", ainda não havia se estruturado um mercado fonográfico satisfatório para o rock no Brasil. Embora agora assimilasse linguagens e estéticas roqueiras - bastaria escutar discos hoje antológicos como Fa-Tal (1971, de Gal Costa), Acabou chorare (1972, dos Novos Baianos) ou Clube da Esquina (1972, de Milton Nascimento e Lô Borges) -, aquilo que se convencionou a chamar de MPB permanecia no topo de nossa hierarquia cultural.

Parente bem próximo do rock, o punk ganha as páginas do livro no artigo assinado por Pedro Minhoni: "A formação da identidade punk no Brasil e o começo do fim do mundo (1976-1982)". A partir de uma descrição historiográfica do show $O$ começo do fim do mundo, ocorrido em 1982 no Sesc Pompéia, em São Paulo, e que reuniu 20 bandas antes que a polícia colocasse fim ao evento, o autor adverte sobre o tom preconceituoso de boa parte da imprensa brasileira em relação ao punk, não raras vezes estigmatizado como apologia da marginalidade, vandalismo e violência. Aos pesquisadores dessa manifestação musical - que, via de regra, reivindicou ser a "antítese" da MPB, àquela altura institucionalizada e "trilha sonora" da abertura política -, caberia perscrutar verdadeiramente novas fontes e materiais empíricos que auxiliem a compreender, em perspectiva histórica e sociológica, as angústias e insatisfações dos jovens que a ela aderiram, evitando, assim, armadilhas de homogeneização.

Se a maioria dos jovens punk, na metrópole de São Paulo, era proveniente de classes populares, o rock que finalmente alcança prestígio na indústria fonográfica brasileira dos anos 1980 teria sido protagonizado, sobretudo, por músicos oriundos da classe média, alguns deles filhos de militares, diplomatas, políticos ou personalidades reconhecidas no meio cultural. $O$ argumento é desenvolvido por Paulo Gustavo da Encarnação em "'Nasci em 62': algumas notas sobre uma breve história social de alguns roqueiros brasileiros dos anos $80^{\prime \prime}$. O autor se pauta nos conceitos de habitus e capital cultural/social de Pierre Bourdieu para discutir o que haveria de semelhante entre bandas cuja escolha foi guiada pelo critério comercial ${ }^{11}$. Nascidos na década de 1960 - daí o título, homônimo ao da canção de Edgard Scandurra, 11 Dentre as bandas e músicos aos quais se refere se encontram, por exemplo, Barão Vermelho, Biquíni Cavadão, Blitz, Camisa de Vênus, Capital inicial, Engenheiros do Hawaii, Ira!, Kid Abelha, Legião Urbana, Nenhum de nós, Os Paralamas do Sucesso, Plebe Rude, RPM, Titãs, Ultraje a Rigor, Ritchie, Lulu Santos e Lobão. 
gravada pelo grupo Ira! -, tais roqueiros expressariam em seus discos a crise de uma "geração rebelde", tanto em relação ao seu pertencimento de classe, do qual usufruíam ${ }^{12}$, quanto em relação ao processo incerto e arrastado de redemocratização, somado ainda a certa descrença nos moldes mais convencionais de mobilização e organização política.

Versando igualmente sobre a década de 1980 em "Rock, cidades e cenas musicais", Érica Maggi articula o rock daquela época com a noção de "cena" e, por consequência, com a problemática da cidade que lhe é intrínseca ${ }^{13}$. De início, tece um paralelo entre as "cenas" de Manchester e São Paulo, para, em seguida, e focando nesta última, insistir sobre o fato de que a metrópole industrial condicionou determinadas dicções atribuídas ao rock, em torno do qual se constituiu todo um aparato de atividades e interações envolvendo lugares, pessoas, públicos e mídias: "cartazes, pôsteres, músicas, casas noturnas, trocas e audições de discos importados, textos da imprensa, programas de rádio, fanzines" (p. 242). Seu foco também se estende para o Rio de Janeiro, embora não demonstre com detalhes em que aspectos se diferenciariam as produções dos roqueiros de ambas as capitais brasileiras naquele momento específico.

Encerrando, assim, a Parte 2, a coletânea nos dá uma amostra de como se encontram os estudos sobre o rock no Brasil, ainda que a maioria dos autores seja ligada a universidades paulistas. Além disso, e dando destaque para temas inevitáveis como contracultura, juventude, vanguarda, experimentalismo, crítica jornalística e mercado musical - mesmo que este último, anunciado no título, apareça às vezes em segundo plano -, oferece caminhos de análise para quem trabalha com a música popular gravada na grande área das Humanidades. Não obstante a abordagem extramusical que prevalece nalguns dos ensaios, principalmente nos derradeiros, um desses caminhos sugeridos pelas Trilhas do rock, no meu ponto de vista o mais desafiante, consiste em compreender que forma musical é um conjunto de

12 Segundo o autor, "o capital social das famílias dos roqueiros muito provavelmente contribuía para que a rebeldia deles, muito antes de alcançarem a posição de ídolos do rock brasileiro, fosse tolerada ou, quando fosse o caso, limitadamente punida pelas autoridades" (p. 203).

13 Cada vez mais comum em pesquisas sobre manifestações musicais contemporâneas, a noção de "cena" - sistematizada inicialmente por Will Straw (1991) - busca designar circuitos de produção e consumo culturais situados em espaços eminentemente urbanos, visando aí descrever alianças, afiliações, lugares comuns de atuação, redes colaborativas e pontos de contato que informariam as práticas e as dinâmicas de grupos juvenis. 
experiências, valores e práticas de caráter estético, histórico e sociocultural a ser examinado. Louvável, portanto, a iniciativa, sobretudo num contexto cujo projeto político só tem dificultado o financiamento público para a pesquisa e a publicação acadêmica no Brasil.

\section{lioro resenhado:}

SOUSA, Rainer Gonçalves (org.). Nas trilhas do rock: experimentalismo e mercado musical. Goiânia: Kelps, 2018. 


\section{referências bibliográficas}

BÜRGER, Peter. Teoria da vanguarda. São Paulo: Cosac Naify, 2008.

CHAUÍ, Marilena; et alii. Onacionale o popularna cultura brasileira: seminários (Vários volumes). São Paulo: Brasiliense, 1982.

CONTIER, Arnaldo Daraya. "Edu Lobo e Carlos Lyra: o nacional e o popular na canção de protesto (os anos 1960)", Revista Brasileira de História, v. 18, n. ${ }^{\circ}$ 35, São Paulo, p. 13-52, 1998.

DINIZ, Sheyla Castro. Desbundados e marginais: MPB e contracultura nos anos de chumbo (1969-1974). Tese de doutorado em Sociologia, Campinas, Unicamp, IFCH, 2017.

FENERICK, José Adriano. "Arrigo Barnabé e o pop rock nos anos 1980", Idéias, Campinas, v. 8, n. 2, p. 13-32, jul./dez., 2017.

HUYSSEN, Andreas. Después de la gran división: modernismo, cultura de massas, pós-modernismo. Buenos Aires: AHE, 1986.

. "A dialética oculta: vanguarda - tecnologia - cultura de massa". In: Memórias do modernismo. Rio de Janeiro: Ed. UFRJ, 1997.

MAMMI, Lorenzo. "A era do disco: o LP não foi apenas um suporte, mas uma forma artística", Piauí, n. 89, p. 36-41, fev. 2014.

MERHEB, Rodrigo. O som da revolução: uma história cultural do rock (19651969). Rio de Janeiro: Civilização Brasileira, 2012.

MIDDLETON, Richard. Studying popular music. London: Open University Press, 1990.

NAPOLITANO, Marcos. "Seguindo a canção": engajamento político e indústria cultural na MPB (1959-1969). São Paulo: Annablume/FAPESP, 2001.

PERONE, James. Music of the counterculture era. Westport: Greenwood Press, 2004 .

RIDENTI, Marcelo. Em busca do povo brasileiro: artistas da revolução, do CPC à era da TV. Rio de Janeiro: Record, 2000. 
STRAW, Will. "System of articulation, logics of change: communities and scenes in popular music", Cultural Studies, London, Taylor \& Francis Group, v. 5, p. 368-388, 1991.

WHITELEY, Sheila. "Contre-culture: musique, théories et scènes", Volume!, La revue des musiques populaires, Contre-culture théories \& scènes, n. 9-1, p. 5-16, Paris, CNRS, 2012.

WILLIAMS, Raymond. Cultura. Rio de Janeiro: Paz e Terra, 1992.

. The long revolution. Peterborough: Broadview Press,

2001.

. Televisão: tecnologia e forma cultural. São Paulo:

Boitempo/Belo Horizonte: PUC-Minas, 2016. 